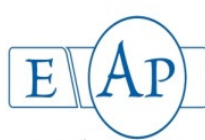

AcademicPres

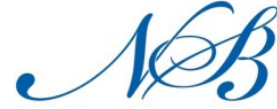

Notulae Scientia Biologicae

\title{
Herbicidal Activity of Coumarin When Applied as a Pre-plant Incorporated into Soil
}

\author{
Amir Hossein NAZEMI, Ghorban Ali ASADI*, Reza GHORBANI
}

\author{
Department of Agronomy and Plant Breeding, College of Agriculture, Ferdowsi University of \\ Mashhad,Mashhad,Iran;asadi@um.ac.ir(*correspondingauthor)
}

\begin{abstract}
Due to having a short half-life and novel site of action, the herbicidal potential of natural compounds are lionized. Coumarin is a secondary metabolite from Lavandula sp., family Lamiacae. The impact of eight concentrations of coumarin (0, 100, 200, 400, 800, 1600, 3200 and 6400 ppm) were separately used as a pre-plant incorporated into soil on six plant species under greenhouse conditions. Generally, coumarin had phytotoxic effect against all plant species. The phytotoxic effect was concentration-dependent. The high concentrations could inhibit the emergence of seedlings (probably by stopping germination of seeds). Based on $\mathrm{ED}_{50}$ parameter, the ranking of plant species for tolerance to coumarin was $S$. halepense $>Z$. mays $>C$. album $>$ A. retroflexus $>$ E. cruss-gali $>$ P. oleracea. Based on selectivity index, coumarin at a concentration of $365.69 \mathrm{ppm}$ can control $P$. oleracea without damaging $Z$. mays, whereas any concentration it cannot control other weeds without damaging Z. mays.
\end{abstract}

Keywords: allelopathy, maize, selectivity index, weed

\section{Introduction}

Various methods to control weeds are always introduced and among them one of the best and modern method is the use of synthetic herbicides (Rashed-Mohassel et al., 2011). Synthetic herbicides offer the same advantages compared to other methods. They are selective, easy to apply, act quickly, are relatively inexpensive, and can be used where other methods do not work well (Zimdahl, 2007). Therefore, their application have increased dramatically in the agricultural world and generated a series of additional problems such as herbicide resistance in weeds, soil and water pollution and the toxicity effects on human health and nontarget species (Zaeri et al., 2013).

In recent years, with increasing the global awareness about these problems, the herbicidal potential of natural compound are lionized due to having very short half-life in the environment (Liet al., 2003) and having novel sites of action (Duke et al., 2002). Many natural compounds have been reported to have herbicidal potential such as artemisinin (a compound isolated from Artemisia annua), ailanthone (a compound isolated from Ailanthus altissima), sorgoleone (a compound isolated from Sorghum sp.), joglan (a compound isolated from Juglans sp.) and so on (Upadhyaya and Blackshaw, 2007). Research progress in this field caused that a secondary metabolite from the Australian bottlebrush (Callistemon citrinus), namely mesotrione, and a secondary metabolite from some lichens, namely sulcotrione, are commercialized as agrochemicals (Duke et al.,2002).

Lavender (Lavandula sp.) is a famous medicinal plant which belongs to the family Lamiacae. The antibacterial (Karamanoli $e t$ al., 2000), antifungal (Moon et al., 2007), insecticidal (Papachristos et al., 2004) and herbicidal activities (Goodwin and Taves, 1950) were demonstrated by the lavender extracts. The herbicidal activity of lavender extracts is due to the main secondary metabolite, so called coumarin. It is a well-known phytotoxin that has been tested in laboratory studies for its effect on germination and growth of some plant species (Chon and Kim, 2004; Pergo et al., 2008; Zaeri et al.,2013).

The current research aimed to determine the herbicidal potential of coumarin on six plant species when applied as a preplant incorporated into soil.

\section{Materials and methods}

The seeds of redroot pigweed (Amaranthus retroflexus), common lambsquarters (Chenopodium album), barnyardgrass (Echinochloa cruss-gali), johnsongrass (Sorghum halepense) and common purslane (Portulaca oleracea) were collected from plants from the field near Mashhad, Iran. The seeds of maize (Zea mays cv. Single Cross 704) were obtained from the Agricultural and Natural Resources Research Center of Mashhad, Iran.

Before the start of the experiment, the seed dormancybreaking treatments were conducted to increase the weed species seeds' coat permeability. Hence, the seeds of $A$. retroflexus, $C$. album, E. cruss-gali, S. halepense, and $P$. oleracea were acid-scarified in concentrated sulfuric acid (98\%) for 5, 1, 3, 4 and $1 \mathrm{~min}$, respectively, then rinsed with distilled water (Zaeri et al., 2013). The seed germination percentages were increased up to $93 \%$ for $E$. cruss-gali and $99 \%$ for $P$. oleracea by the aforementioned method. 
240

Bioassays were conducted between June and September 2014 in a greenhouse located on the Ferdowsi University of Mashhad, Iran. Six experiments were separately set up as a completely randomized design with eight treatments (eight concentrations). There were four replications. A mixture of sand and clay loam soil $(1: 1 \mathrm{v} / \mathrm{v})$ in $1.5 \mathrm{~L}$ plastic pots was supplied. Then, $30 \mathrm{ml}$ of a coumarin solution of 0 (control), 100, 200, 400, 800, 1600, 3200 and $6400 \mathrm{ppm}$ were added to each pot, and then incorporated with upper layer of soil mixture. Then, 25 seeds of the aforementioned plant species were separately planted at $0.5 \mathrm{~cm}$ depth in each pot. The pots were irrigated every 5 days with tap water.

Four weeks after planting, the total number of emerged seedlings was determined; then shoots of the plants in each pot were harvested and oven-dried at $75^{\circ} \mathrm{C}$ for a period of $48 \mathrm{~h}$ and the dry weight was determined.

The data were changed to individual plant and subjected to analyze by two variance analysis using PROC GLM in SAS and the non-linear regression analysis using open-source statistical software, $\mathrm{R}_{262}$, using the $d r c$ statistical addition package. The response of each plant species (the biomass produced of individual plants in pot) to coumarin concentration was assumed separately using two log-logistic models ( 3 or 4 parameters) that were described elaborately by Tind et al. (2009) as follows; respectively:

$$
\begin{aligned}
& Y=C+\left\{D-C / 1+\exp \left[b\left(\log X-\log E D_{50}\right)\right]\right\} \\
& Y=D / 1+\exp \left[b\left(\log X-\log E D_{50}\right)\right]
\end{aligned}
$$

where:

' $Y$ ' is the response (dry weight);

' $C$ ' is the lower limit;

'D' is the upper limit corresponding to the response of the untreated control;

' $\mathrm{b}$ ' is the slope of the line;

'ED' is the required concentration of coumarin to give $50 \%$ control;

' $\mathrm{X}$ ' is the coumarin concentration.

The coumarin concentration needed to obtain $10 \%$ and $90 \%$ reduction in dry weight $\left(\mathrm{ED}_{10}\right.$ and $\mathrm{ED}_{90}$, respectively) were also determined. The ratio between the concentration that caused $10 \%$ of damage to maize and $90 \%$ of damage to each weed was used as a selectivity index. According to Tind et al. (2009), a selectivity index above 2 can be safely used in a crop.

\section{Results and discussions}

Generally, the produced biomass of all plant species under study was significantly $(\mathrm{P} \leq 0.01)$ influenced when coumarin was applied as a pre-plant incorporated into soil (Table 1). There were differences between the different concentrations of coumarin over inhibition of the germination and growth of the tested plant species. The phytotoxic effect was concentrationdependent. These differences are reported in detail in the following sections. At high amount of coumarin, the seeds did not emerge (probably did not germinate) and/or the seedlings emerged with short and pale leaves. In this regard, P. oleracea had a small number of seedlings that were observed alive in experimental units (Table 1).

Exhaustively, the phytotoxic effect of coumarin on E. crussgali enhanced with increasing its concentration (Table 1). A concentration of $100 \mathrm{ppm}$ reduced significantly the dry weight of E. cruss-gali from $2.62 \mathrm{~g}$ (control) to $1.70 \mathrm{~g}$. Relative to the control, the greatest reduction in the dry weight of $E$. cruss-gali was observed with applying a concentration of $3200 \mathrm{ppm}$. There were no significant differences between 3200 and $6400 \mathrm{ppm}$. The application of a concentration of $6400 \mathrm{ppm}$ coumarin inhibited completely the emergence (probably germination) of E. cruss-gali. Coumarin is a well-known phytotoxin that has been tested in laboratory studies for its effect on germination and growth of some plant species such as wild oats (Avena fatua) (Goodwin and Taves, 1950), timothy grass (Pbleum pratense) (Avers and Goodwin, 1956), alfalfa (Medicago sativa), velvetleaf (Abutilon theophrasti) and ryegrass (Lolium multiflorum) (Dornbos and Spencer, 1990), barnyard grass (Echinochloa crusgalli) (Chon and Kim, 2004) and beggar' sticks (Bidens pilosa) (Pergo et al., 2008). Haig et al. (2009) also reported that coumarin applied to post-emergence at a concentration of 100 ppm resulted in a reduction by almost $80 \%$ in annual ryegrass (Lolium rigidum) shoot weight.

In case of $A$. retroflexus, the lowest coumarin concentration had a significant herbicidal effect so that when coumarin was applied at a concentration of $100 \mathrm{ppm}$, it reduced significantly the dry weight of $A$. retroflexus from $2.48 \mathrm{~g}$ (control) to $1.02 \mathrm{~g}$. Nevertheless, no significant difference was observed among the

\begin{tabular}{|c|c|c|c|c|c|c|}
\hline \multirow{2}{*}{ Coumarin (ppm) } & \multicolumn{6}{|c|}{ Shoot dry weight (g) } \\
\hline & Z. mays & S. halepense & E. cruss-gali & A. retroflexus & C. album & P. oleracea \\
\hline 0 (control) & $3.81 \mathrm{a}$ & $4.01 \mathrm{a}$ & $2.62 \mathrm{a}$ & $2.48 \mathrm{a}$ & $1.79 \mathrm{a}$ & $2.31 \mathrm{a}$ \\
\hline 100 & $2.66 \mathrm{~b}$ & $3.18 \mathrm{a}$ & $1.70 \mathrm{~b}$ & $1.02 \mathrm{~b}$ & $1.41 \mathrm{~b}$ & $1.34 \mathrm{~b}$ \\
\hline 200 & $3.01 \mathrm{bc}$ & $3.26 \mathrm{a}$ & $1.10 \mathrm{c}$ & $2.08 \mathrm{~b}$ & $1.10 \mathrm{~b}$ & $0.23 \mathrm{c}$ \\
\hline 400 & $2.59 \mathrm{~b}$ & $1.98 \mathrm{~b}$ & $0.51 \mathrm{~d}$ & $0.83 \mathrm{~b}$ & $0.62 \mathrm{c}$ & $0.23 c$ \\
\hline 800 & $2.76 \mathrm{~b}$ & $1.69 \mathrm{c}$ & $0.28 \mathrm{de}$ & $0.33 \mathrm{c}$ & $0.18 \mathrm{~d}$ & $0.21 \mathrm{c}$ \\
\hline 1600 & $2.30 \mathrm{~b}$ & $1.31 \mathrm{~cd}$ & $0.10 \mathrm{e}$ & $0.12 c$ & $0.12 \mathrm{~d}$ & $0.00 \mathrm{c}$ \\
\hline 3200 & $1.01 \mathrm{c}$ & $0.56 \mathrm{~d}$ & $0.10 \mathrm{e}$ & $0.00 \mathrm{c}$ & $0.02 \mathrm{~d}$ & $0.00 \mathrm{c}$ \\
\hline 6400 & $0.52 c$ & $0.62 \mathrm{~d}$ & $0.00 \mathrm{e}$ & $0.00 \mathrm{c}$ & $0.00 \mathrm{~d}$ & $0.00 \mathrm{c}$ \\
\hline $\mathrm{LSD}=0.05$ & 0.90 & 0.84 & 0.39 & 0.36 & 0.29 & 0.27 \\
\hline ANOVA & \multicolumn{6}{|c|}{ Mean squares } \\
\hline Concentration (d.f. $=7$ ) & $4.82 * *$ & $6.24 * *$ & $3.53 * *$ & $3.83 * *$ & $2.24 * *$ & $2.84 * *$ \\
\hline Error (d.f. $=24$ ) & 0.22 & 0.36 & 0.08 & 0.11 & 0.15 & 0.04 \\
\hline CV $(\%)$ & 24.93 & 17.69 & 15.53 & 14.74 & 21.01 & 25.09 \\
\hline
\end{tabular}

Table 1. The effects of different concentrations of coumarin when applied as a pre-plant incorporated into soil on the produced biomass 
Table 2. Estimated parameters for the dose-response curves

\begin{tabular}{|c|c|c|c|c|c|c|c|}
\hline Selectivity index & $\begin{array}{l}\mathrm{ED}_{90} \\
(\mathrm{ppm})\end{array}$ & $\begin{array}{l}\mathrm{ED}_{50} \\
(\mathrm{ppm})\end{array}$ & $\begin{array}{c}\mathrm{ED}_{10} \\
(\mathrm{ppm})\end{array}$ & $\begin{array}{l}\text { Upper limit } \\
\text { (g) }\end{array}$ & $\begin{array}{c}\text { Lower limit } \\
(\mathrm{g})\end{array}$ & Slope & Plants \\
\hline- & 16252.80 & 370.33 & 365.69 & 3.26 & - & 1.14 & Z. mays \\
\hline 0.06 & 5743.58 & 467.78 & 38.09 & 4.01 & 0.24 & 0.87 & S. halepense \\
\hline 0.44 & 777.08 & 156.22 & 31.40 & 2.62 & 0.27 & 1.36 & E. cruss-gali \\
\hline 0.40 & 847.06 & 212.23 & 53.17 & 2.54 & - & 1.58 & A. retroflexus \\
\hline 0.43 & 792.36 & 266.70 & 89.76 & 1.83 & - & 2.01 & C. album \\
\hline 2.06 & 167.97 & 101.41 & 57.34 & 2.32 & - & 3.44 & P. oleracea \\
\hline
\end{tabular}

$\mathrm{ED}_{10}$ of Z. mays / ED90 of each weed were used to calculate the selectivity index
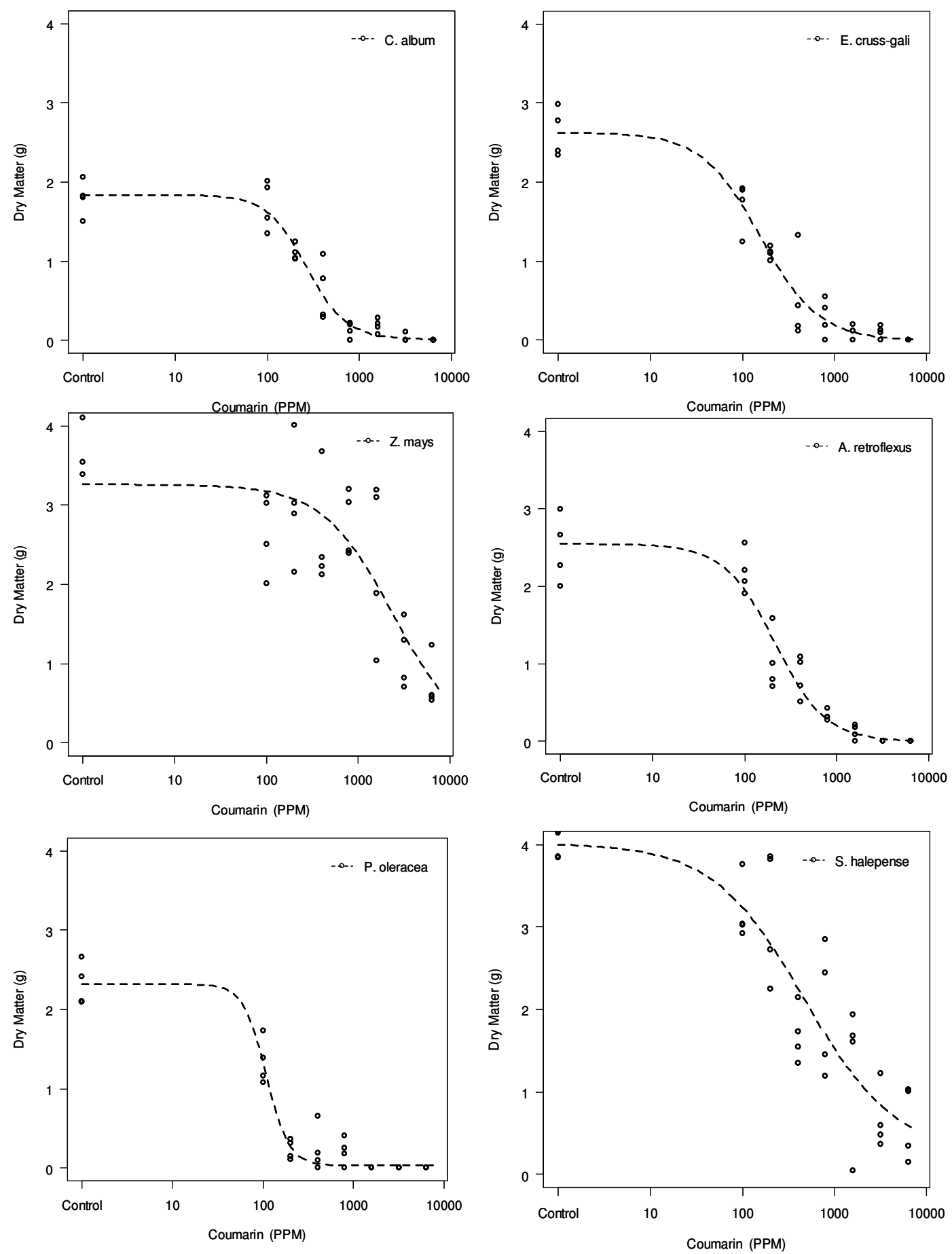

Fig. 1. Dose-response curves of the dry weight of plants on different concentrations of coumarin applied as a pre-plant incorporated into soil. The points are the replications of each treatment 
242

treatments of $100-400 \mathrm{ppm}$. Relative to the control, the greatest reduction in the dry weight was observed at the concentrations of 3200 and $6400 \mathrm{ppm}$. The application of these two concentrations inhibited completely the emergence (probably germination) of A. retroflexus (Table 1 ).

As compared with other plant species, it seems that $P$. oleracea was very sensitive to coumarin so that the application of highest three concentrations of 1600, 3200, and $6400 \mathrm{ppm}$ inhibited completely its emergence (probably germination). The lowest coumarin concentration had a significant herbicidal effect on $P$. oleracea. As with applying a concentration of $100 \mathrm{ppm}$, the produced dry weight of $P$. oleracea was reduced from $2.31 \mathrm{~g}$ (control) to $1.34 \mathrm{~g}$ (Table 1).

In case of $Z$. mays, the phytotoxic effect of coumarin rose with increasing its concentration (Table 1 ). When coumarin was applied at a concentration of $100 \mathrm{ppm}$, the produced dry weight of $Z$. mays reduced significantly from $3.81 \mathrm{~g}$ (control) to $2.66 \mathrm{~g}$. No significant difference was observed among the concentrations of 100-1600 ppm. The highest reduction in dry weight of $Z$. mays was obtained with application of $6400 \mathrm{ppm}$ $(0.52 \mathrm{~g})$. Nevertheless, no significant difference was observed between the treatments of 3200 and $6400 \mathrm{ppm}$. Unlike E. crussgali, $P$. oleracea, and $A$. retroflexus, some seeds of $Z$. mays were able to emerge in all concentrations of coumarin applied as a preplant. The reason for this behavior (relative tolerance) may be attributed to two factors: i) large-seeded $Z$. mays versus smallseeded weed. The previous studies indicated that small-seeded species appear especially susceptible to allelochemicals because the surface-to-volume ratio of a small-seeded species is usually greater, and therefore its exposure per unit mass to allelopathic substances in the soil is also greater (Chase et al., 1991; Putnam and DeFrank, 1983); ii) High rate of metabolism. The previous studies indicated that the metabolism of coumarin by maize, wheat (Zaeri et al., 2013) and canola (Haig et al., 2009) appears to play an important role in the relative tolerance to low concentrations of coumarin and involves mainly oxidation, reduction and/or hydrolysis.

As compared with other plant species, the lowest coumarin concentration (100 ppm) did not have any significant effect on $S$. halepense. But coumarin applied at a concentration of 400 $\mathrm{ppm}$ reduced significantly the produced dry weight of $S$. halepense from $4.01 \mathrm{~g}$ (control) to $1.98 \mathrm{~g}$ (Table 1). No significant difference was observed among the treatments of 0 (control)-200 ppm. The toxicity of coumarin for $S$. halepense increased with increasing its concentration. The highest reduction in dry weight of $S$. halepense was obtained with application of $3200 \mathrm{ppm}(0.56 \mathrm{~g})$. Nevertheless, no significant difference was observed among the concentrations of 1600-6400 $\mathrm{ppm}$. Like maize, some seeds of $S$. halepense were able to emerge in all concentrations of coumarin applied. Given that $S$. halepense is a small-seeded weed, it seems that the plant metabolism plays a primary role in the relative tolerance to coumarin.

In the case of $C$. album, the phytotoxic effect of coumarin enhanced with increasing its concentration (Table 1). When coumarin was applied at a concentration of $100 \mathrm{ppm}$, it significantly reduced the dry weight of C. album from $1.79 \mathrm{~g}$ (control) to $1.41 \mathrm{~g}$. Relative to the control, the greatest reduction in the dry weight of C. album was observed at the concentration of $3200 \mathrm{ppm}$. There were no significant differences between 3200 and $6400 \mathrm{ppm}$. The application of a concentration of 6400 ppm coumarin inhibited completely the emergence (probably germination) of C. album.

Dose-response curves for coumarin against the tested species are shown in Fig. 1. Table 2 summarized the parameters for these dose-response curves. Based on the $\mathrm{ED}_{50}$ parameter, the coumarin concentration needed to obtain $50 \%$ reduction in dry weight of $S$. halepense, Z. mays, C. album, A. retroflexus, E. crussgali and $P$. oleracea equal to $467.78,370.33,266.70,212.23$, 156.22 and $101.41 \mathrm{ppm}$, respectively. Therefore, the most tolerant and sensitive to the coumarin application were $S$. halepense and $P$. oleracea, respectively. The values of selectivity index $\left(\mathrm{ED}_{10}\right.$ for $Z$. mays / $\mathrm{ED}_{90}$ for each weed) showed that with the exception of $P$. oleracea, the value of selectivity index of coumarin measured for $Z$. mays to control other weeds was less than 2 (Table 2). Therefore, coumarin can only be used selectively to control $P$. oleracea in $Z$. mays.

\section{Conclusions}

The results of this study confirmed not only the previous results, but also showed that coumarin has the phytotoxic effect against $Z$. mays, S. halepense, E. cruss-gali, A. retroflexus, C. album and $P$. oleracea. Generally, $S$. halepense and $P$. oleracea were the most tolerant and sensitive to coumarin when applied as a preplant incorporated into soil, respectively. A correlation between seed size and tolerance/sensitive to coumarin was founded, as small-seeded species appear more sensitive to coumarin. Based on the values of selectivity index, coumarin at a concentration of $365.69 \mathrm{ppm}$ can only be used selectively to control $P$. oleracea in $Z$. mays. An additional approach for enhancing selectivity of coumarin is required by using a proper safener.

\section{Acknowledgements}

This work was conducted in partial fulfillment of requirements for the Ph.D. degree (Project No. 3/30393) in Weed Science at Ferdowsi University of Mashhad that funded by a grant from the College of Agriculture. Hereby, it is acknowledged.

\section{References}

Avers CJ, Goodwin RH (1956). Effects of coumarin and scopoletin on the standard root growth pattern of Pbleum pratense. Amer J Bot 43:612-620.

Chon SU, Kim YM (2004). Herbicidal potential and quantification of suspected allelochemicals from four grass crop extracts. J Agron Crop Sci 190:145-150.

Chase WR, Nair MG, Putnam AR (1991). 2,2'-oxo-1,1'-azobenzene: selective toxicity of rye (Secale cereal L.) allelochemicals to weed and crop species.J Chem Ecol 17:9-19.

Dornbos DL, Spencer GF (1990). Natural products phytotoxicity-a bioassay suitable for small quantities of slightly water-soluble compounds.J Chem Ecol 16:339-352.

Duke SO, Dayan FE, Rimando AM, Schrader KK, Aliotta G, Oliva A, Romagni JG (2002). Chemicals from nature for weed management. Weed Sci 50:138-151.

Goodwin RH, Taves C (1950). The effect of coumarin derivatives on the growth of Avena roots. Amer J Bot 37:324331. 
Haig TJ, Seal AN, Pratley JE, An M, Wu H (2009). Lavender as a source of novel plant compounds for the development of a natural herbicide.J Chem Ecol 35:1129-1136.

Karamanoli K, Vokou D, Spiroudi UM, Constantinidou HIA (2000). Bacterial colonization of philosopher of Mediterranean aromatic plants. J Chem Ecol 26:2035-2048.

Li Y, Sun Z, Zhuang X, Xu L, Chen S, Li M (2003). Research progress on microbial herbicides. Crop Prot 22:247-252.

Moon T, Cavanagh HMA., Wilkinson JM (2007). Antifungal activity of Australian grown Lavandula spp. essential oils against Aspergillus nidulans, Trichophyton mentagrophytes, Leptosphaeria maculans and Sclerotinia sclerotiorum. J Ess Oil Res 19:171-175.

Papachristos DP, Karamanoli KI, Stamopoulos DC, Spiroudi UM (2004). The relationship between the chemical composition of three essential oils and their insecticidal activity against Acanthoscelides obtectus (Say). Pest Manage Sci 60:514-520.

Pergo EM, Abrahim D, Dasilva PCS, Kern KA, Dasilva LJ, Voll E, IshiiIwamoto EL (2008). Bidens pilosa L. exhibits high sensitivity to coumarin in comparison with three other weed species. J Chem Ecol 34:499-507.
Putnam AR, DeFrank J (1983). Use of phytotoxic plant residues for selective weed control. Crop Prot 2:173-81.

Rashed-Mohassel MH, Aliverdi A, Rahimi S (2011). Optimizing dosage of sethoxydim and fenoxaprop-p-ethyl with adjuvants to control wild oat. Ind Crop Prod 34:1583-1587.

Tind T, Mathiesen TJ, Jensen JE, Ritz C, Streibig JC (2009). Using a selectivity index to evaluate logarithmic spraying in grass seed crops. Pest Manage Sci 65:1257-1262.

Upadhyaya MK, Blackshaw RE (2007). Non-chemical weed management: principles, concepts and technology. $\mathrm{CAB}$ International, London, $\mathrm{UK}$.

Zaeri MJ, Alimoradi L, Sohani-Darban AR, Banezhad Z (2013). Allelopathic behavior of coumarin on germination and seedling growth of weeds and crops. Adv Crop Sci 13:751-761.

Zimdahl RL (2007). Fundamentals of Weed Science, $3^{\text {rd }}$. Academic Press, USA. 